\begin{tabular}{|c|c|}
\hline Citation & $\begin{array}{l}\text { Meyfroidt G, Ingels C, (2011), } \\
\text { Glycemic control in the ICU. } \\
\text { N Engl J Med. } 2011 \text { Mar 31;364(13):1280; author reply } 1281\end{array}$ \\
\hline Archived version & Final publisher's version / pdf \\
\hline Published version & http://dx.doi.org/10.1056/NEJMc1100698\#SA1 \\
\hline Journal homepage & http://content.nejm.org/ \\
\hline Author contact & $\begin{array}{l}\text { your email greet.vandenberghe@med.kuleuven.be } \\
\text { your phone number + } 32(0) 16344021\end{array}$ \\
\hline IR & https://lirias.kuleuven.be/handle/123456789/311548 \\
\hline
\end{tabular}

(article begins on next page) 
data strongly suggest that, in addition to recessively inherited syndromes such as the mosaic variegated aneuploidy syndrome, haploinsufficiency of spindle-assembly checkpoint components may underlie early-onset gastrointestinal cancers that may be prevented by surveillance.

Richarda M. de Voer, Ph.D.

Nicoline Hoogerbrugge, M.D., Ph.D.

Roland P. Kuiper, Ph.D.

Radboud University Nijmegen Medical Center

Nijmegen, the Netherlands

r.kuiper@antrg.umcn.nl
No potential conflict of interest relevant to this letter was reported.

1. Rio Frio T, Lavoie J, Hamel N, et al. Homozygous BUB1B mutation and susceptibility to gastrointestinal neoplasia. $\mathrm{N}$ Engl J Med 2010;363:2628-37.

2. Scully R. The spindle-assembly checkpoint, aneuploidy, and gastrointestinal cancer. N Engl J Med 2010;363:2665-6.

3. Rao CV, Yang YM, Swamy MV, et al. Colonic tumorigenesis in BubR1+/-ApcMin/+ compound mutant mice is linked to premature separation of sister chromatids and enhanced genomic instability. Proc Natl Acad Sci U S A 2005;102:4365-70.

4. Baker DJ, Jin F, Jeganathan KB, van Deursen JM. Whole chromosome instability caused by Bub1 insufficiency drives tumorigenesis through tumor suppressor gene loss of heterozygosity. Cancer Cell 2009;16:475-86.

\section{Glycemic Control in the ICU}

TO THE EDITOR: Kavanagh and McCowen (Dec. 23 issue) ${ }^{1}$ recommend a glycemic target range of 140 to $180 \mathrm{mg}$ per deciliter for a patient with pneumonia in an intensive care unit (ICU) who had an increase in the arterial glucose concentration from a level of $105 \mathrm{mg}$ per deciliter to $195 \mathrm{mg}$ per deciliter. This recommendation is surprising to us, given the evidence.

Until 2001, neglecting hyperglycemia was standard ICU care. The proof of concept for hyperglycemia-induced toxic effects came from a randomized, controlled trial involving patients in a surgical ICU, ${ }^{2}$ in which normoglycemia (glucose level, 80 to $110 \mathrm{mg}$ per deciliter) improved outcome, as compared with tolerating hyperglycemia to a level of $210 \mathrm{mg}$ per deciliter. Studies documenting the transition from neglecting hyperglycemia to targeting normoglycemia showed similar benefits. ${ }^{3}$ Confirmative data subsequently came from large, single-center, randomized, controlled trials, one involving adult patients in a medical ICU (which showed morbidity benefits) ${ }^{4}$ and one involving patients in a pediatric ICU (which showed improved survival). ${ }^{5}$ Studies in animals have elucidated the underlying mechanisms of this benefit. Multicenter studies that used different protocols and inaccurate glucose meters and that compared intermediate glycemia with normoglycemia argued against the generalizability of these findings.

But where is the randomized, controlled trial comparing the target of 140 to $180 \mathrm{mg}$ per deciliter against neglecting hyperglycemia? Currently, no evidence supports this intermediate target, which might still evoke risks, such as hypoglycemia, glycemic fluctuations, and hypokalemia. ${ }^{6}$ The current data support the choice between targeting normoglycemia or no treatment. Is not any target of 110 to $200 \mathrm{mg}$ per deciliter rather a pragmatic choice driven by the unavailability of accurate tools to measure and stably control blood glucose? Also, would the recommendation imply that clinicians should infuse glucose to treat a spontaneous glucose concentration of less than $140 \mathrm{mg}$ per deciliter?

Geert Meyfroidt, M.D., Ph.D.

Catherine Ingels, M.D.

Greet Van den Berghe, M.D., Ph.D.

Catholic University of Leuven

Leuven, Belgium

greet.vandenberghe@med.kuleuven.be

No potential conflict of interest relevant to this letter was reported.

1. Kavanagh BP, McCowen KC. Glycemic control in the ICU. N Engl J Med 2010;363:2540-6.

2. Van den Berghe G, Wouters $P$, Weekers F, et al. Intensive insulin therapy in critically ill patients. N Engl J Med 2001; 345:1359-67.

3. Krinsley JS. Effect of an intensive glucose management protocol on the mortality of critically ill adult patients. Mayo Clin Proc 2004;79:992-1000. [Erratum, Mayo Clin Proc 2005;80:1101.] 4. Van den Berghe G, Wilmer A, Hermans G, et al. Intensive insulin therapy in the medical ICU. N Engl J Med 2006;354:449-61. 5. Vlasselaers D, Milants I, Desmet L, et al. Intensive insulin therapy for patients in paediatric intensive care: a prospective, randomised controlled study. Lancet 2009;373:547-56.

6. Meyfroidt G, Keenan DM, Wang X, Wouters PJ, Veldhuis JD, Van den Berghe G. Dynamic characteristics of blood glucose time series during the course of critical illness: effects of intensive insulin therapy and relative association with mortality. Crit Care Med 2010;38:1021-9. 
THE AUTHORS REPLY: The original 2001 report $^{1}$ by Van den Berghe et al. provided important preliminary data. It was assumed that intensive insulin therapy provided benefit, but because of the design, it is also possible that the control management caused harm. Despite this uncertainty, intensive insulin therapy was prematurely and widely implemented. However, the authors' 2006 study $^{2}$ was not confirmatory, since intensive insulin therapy resulted in no benefit in the primary outcome of in-hospital mortality. Although a secondary analysis suggested reduced mortality in "long stay" patients, this finding implied that there was a reciprocally increased rate of death in the "short stay" group. ${ }^{3}$ In addition, the reported morbidity benefits have not been replicated in subsequent studies. ${ }^{4}$ The control management in the Normoglycemia in Intensive Care EvaluationSurvival Using Glucose Algorithm Regulation (NICE-SUGAR) study 5 constituted a moderate glycemic-control strategy ( $<180 \mathrm{mg}$ per deciliter), necessitating substantial amounts of insulin. ${ }^{5}$ Such a glucose target is not "neglect," and the strategy was associated with a lower mortality than was intensive insulin therapy. We recommend the infusion of glucose only to provide energy or to treat hypoglycemia. Our recommendations are not surprising; they are consistent with best estimates from available data and are reflected in those guidelines that have been updated.

Brian P. Kavanagh, M.B.

University of Toronto

Toronto, ON, Canada

brian.kavanagh@sickkids.ca

Karen C. McCowen, M.D.

Harvard Vanguard Medical Associates

Boston, MA

Since publication of their article, the authors report no further potential conflict of interest.

1. Van den Berghe G, Wouters P, Weekers F, et al. Intensive insulin therapy in critically ill patients. N Engl J Med 2001; 345:1359-67.

2. Van den Berghe G, Wilmer A, Hermans G, et al. Intensive insulin therapy in the medical ICU. N Engl J Med 2006;354:44961.

3. Malhotra A. Intensive insulin in intensive care. $\mathrm{N}$ Engl $\mathrm{J}$ Med 2006;354:516-8.

4. Marik PE, Preiser J-C. Toward understanding tight glycemic control in the ICU: a systematic review and metaanalysis. Chest 2010;137:544-51.

5. The NICE-SUGAR Study Investigators. Intensive versus con- ventional glucose control in critically ill patients. $\mathrm{N}$ Engl J Med 2009;360:1283-97.

Correspondence Copyright @) 2011 Massachusetts Medical Society.

\section{INSTRUCTIONS FOR LETTERS TO THE EDITOR}

Letters to the Editor are considered for publication, subject to editing and abridgment, provided they do not contain material that has been submitted or published elsewhere. Please note the following:

- Letters in reference to a Journal article must not exceed 175 words (excluding references) and must be received within 3 weeks after publication of the article.

- Letters not related to a Journal article must not exceed 400 words.

- A letter can have no more than five references and one figure or table.

- A letter can be signed by no more than three authors.

- Financial associations or other possible conflicts of interest must be disclosed. Disclosures will be published with the letters. (For authors of Journal articles who are responding to letters, we will only publish new relevant relationships that have developed since publication of the article.)

- Include your full mailing address, telephone number, fax number, and e-mail address with your letter.

- All letters must be submitted at authors.NEJM.org.

Letters that do not adhere to these instructions will not be considered. We will notify you when we have made a decision about possible publication. Letters regarding a recent Journal article may be shared with the authors of that article. We are unable to provide prepublication proofs. Submission of a letter constitutes permission for the Massachusetts Medical Society, its licensees, and its assignees to use it in the Journal's various print and electronic publications and in collections, revisions, and any other form or medium.

\section{CORRECTIONS}

Case 7-2011: A 52-Year-Old Man with Upper Respiratory Symptoms and Low Oxygen Saturation Levels (March 10, 2011;364: 957-66). In the legend for Figure 2 (page 964), the penultimate sentence should have read, "The duodenal-biopsy specimen (Panel C, hematoxylin and eosin) shows blunted and atrophic villi (long arrow), crypt hyperplasia (short arrows) . . . , rather than ". . . shows blunted and atrophic villi (short arrows), crypt hyperplasia (long arrow). . . ." The article is correct at NEJM.org.

Diabetes Mellitus, Fasting Glucose, and Risk of Cause-Specific Death (March 3, 2011;364:829-41). In the Discussion (page 837), the second sentence should have ended, ". . . . the reduction in life expectancy from long-term cigarette smoking is about 10 years," rather than ". . . . about 7 years." The article is correct at NEJM.org.

Long-Acting Risperidone and Oral Antipsychotics in Unstable Schizophrenia (March 3, 2011;364:842-51). In Figure 2 (page 847), the $\mathrm{x}$-axis should have been labeled "Freedom from Hospitalization," rather than "Probability of Hospitalization." The article is correct at NEJM.org. 